are depressants of the circulation, and which paralyse the hind legs of animals without affecting their fore legs. Among these, I mention aconitia, conia, and, doubtfully, veratria and chloral; with reference to prussic acid, it is said to benumb the hind legs first.

Again, for other instances, take the very complete paraplegia of the lower extremities, which so much impressed Dr. Bristowe in the highly interesting cases of rupture of abdominal aneurysm which he recently published. Surely, if we consider the mode in which the arterial supply of the spinal cord would be reduced by the bursting of the aneurysm, the paraplegia in these cases is immediately comprehensible. Again, if we take the so-called urinary paraplegia, or functional paraplegia of any kind, including what is called hysterical paraplegia, we find these affections never troubling the upper limbs, but always the lower. And I think the point $I$ have raised will suggest lines of investigation that may throw great light on this obscure class of nervous diseases. I believe that it is by impediment to the exceedingly and peculiarly difficult blood-supply of the caudal end of the spinal cord that all these various conditions lead to paralytic weakness of the lower limbs, and they are to be met by conditions improving the circulation, if possible.

Why the lumbar cord should be thus straitly supplied, is an interesting question. Perhaps it may be connected with a necessity that the economy should be so organised as to feel fatigue early enough in the parts which directly put iforth exhausting exertion, lest strain of effort should first overtake more vital parts than secondarily share in all such exertion. In short, the cord is supplied scantily, so that we should sit down when we have walked enough, and lie down when we are tired; and, especially, that we should, if necessary, fall down when faintness. overtakes us, to the end that, in the horizontal position, the circulation may be able to restore itself.

\section{THE NATURAL HISTORY OF LEUCODERMA.}

THE natural history of the rarer skin-diseases has been as yet but scarcely half investigated. How they develope themselves, and what they are in mid-course is well known; but what ultimately becomes of them has evidently been as yet insufficiently studied. A pungent proof of this was afforded by a recent delate at the Clinical Society (at which I was present), when competent men who.had for long devoted their special attention to the study of skin diseases were found arrayed against one another in about equal number on the question, what ultimately becomes of keloids? some declaring that they always disappeared spontaneously; and some that they absolutely never disappeared spontaneously. In fact, it was clear that the majority of those who spoke did not know whether it was one way or the other.

As regards leucoderma, I venture to say our knowledge is not very much better. I therefore beg to contribute a well authenticated fact respecting it. My old schoolfellow $H$. B., has lately returned from India. His judicial and administrative functions had brought him in contact with a fairly considerable number of lepers. This had led him to take an interest in leprosy, and so, also, in the skin-diseases with which it is liable to be confounded. So strong a leaning has my friend H. B. for medical studies, that he almost thinks of sacrificing a high lay position for the sake, even now, of turning doctor. His medical knowledge is considerable, but his acquaintance with the subject of skin disease is superior to that of the majority of practitioners, I therefore accept his account of himself. He informs me that he had leucoderma, and that his leucoderma had spontaneously and completely vanished within a fairly short period. His age is forty-five. His leucoderma affected the backs of both of his hands (a favourite position for it), but affected no other part of him. It appeared when he was thirty-eight. It had disappeared completely by the time he was forty-four. It waned more rapidly than it had waxed. It did not affect his wrists or his fingers, but only the backs of his hands. It consisted, on each hand, of a single milk white patch of the aggregate size of a crown piece, and having a sinuous margin. The brown areola was sharply defined on its inner margin, but faded gradually off at its outer margin. It is clear that my friend had leucoderma. It is equally clear that his leucoderma disappeared spontaneously within a period of six years. This fact is interesting to know, but it would be of more interest to learn whether this is the usual course pursued by leucoderma. The inquiry is a diffcult one, because those who would be most likely to take interest in the question, have the least opportunity of following up their cases. The most likely way of solving the point seems to offer itself in the inquiry "Do piebald negroes or piebald Hindoos ever cease to be piebald?" It ought not to be a difficult matter to come at that.

As we do not know how to cure leucoderma it would be an advantage to be able to tell our patients, if we can, that it will go away of itself even if they have to wait six years for it.

Balmanno Squire, M.B.Lond.

\section{THE GULSTONIAN LECTURES on} A N $Æ$ M I A.

Delivered before the Royal College of Physicians.

BY SIDNEY COUPLAND, M.D., F.R.C.P., Physician to the Middlesex Hospital.

LECTURE II.-PART I.

Idiopathic Anamia: Earliest Recognition of it by Addison-Records of Cases $(1851+187 x)$ by Barclay; Lebert, Wilks, Habershon, KingGusserow-Biermer's New Departure (I87I)-Growth of its Litera. ture in the last Decade-Wide Extension given to the Term "Per. nicious"-Clinical Features of "Pernicious" Anamia-Onsit-Progress-Digestive, Circulatory, and Nervous Symptoms-HamorrhageIrregular Pyrexia-Duration-Termination in Recovery-In Recovery followed by Relapse-In Death-Post Mortem Appearances.

Mr. President and Gentlemen,-It is impossible to speak of idiopathic anæmia without reference to Addison, for he it was who seems to have distinctly called attention to a class of cases in which anæmia is the prevailing symptom from first to last-an anæmia not depending upon recognised causes, not associated with wasting of the tissues, but insidious in its onset and slowly downward in its progress, revealing after death no changes but those of fatty degeneration, especially of the heart. The passage in which he summed up his experience of this condition occurs early in his essay on Disease of the Suprarenal Capsules: * This passage has been so often quoted, that it is hardly necessary for me to repeat it now, much as I am tempted to do so, for it is a model of a succinct summary of clinical observation. It was written in 1855, but Addison's observations dated far before that period, and indeed he described the condition in his lectures as early as 1843. + There is no doubt also that similar cases had been observed, and a few recorded, about the same period. In 1851, Dr. Barciay published the notes of two fatal cases of anæmia (Medical Times, 1851 , vol.?i, p. 480) occurring in St. George's Hospital. One was the case of a man aged 34, admitted under Dr. Page on January 2 Ist, I852. He had been ailing for twelve months, and had suffered from inconstant aching pain in the loins, accompanied by scanty loaded urine. He had lately lost flesh and had a slight cough, was remarkably pallid, complained of shortness of breath and palpitation; pulse 120 , and very weak; and he suffered from constipation. There was deficient breathsound at both apices, especially the right, where it was distant and tubular ; there was then no cardiac murmur. A fortnight later he was attacked by romiting. A bellows-murmur with the systole developed, best heard in the mid-præcordia and towards the apex. He rather rapidly passed into a state of exhaustion, ending in coma, on February I th. Mr. P. Hewett, who made the necropsy, found the body well nourished, the brain very anæmic, a few extravasations in the pia mater, cretified deposits at the apex of the right lung, emphysema elsewhere, the posterior.parts being engorged with frothy serum. The heart was healthy and pale, but contained large fibrinous clots in all its cavities. The abdominal viscera were bloodless, and a few cysts were observed in the left kidney. The dark and healthy colour of the muscles was observed in contrast with the pallor of the integument, and the extremely yellow colour of the subcutaneous fat was also noted: The other case was that of a married woman with several children, admitted under Dr. Wilson on January 29 th, 1851 . She had not been well since her last confinement, four months before; she had been weak, but had not suffered from hæmorrhage; she had, however, been troubled with diarrhœa for two months previously. She was extremely anæmic ; pulse quick, feeble, and empty; appetite bad; urine scanty and loaded; her only complaint was of general weakness. The diarrhoea was checked by remedies, but she did not gain strength. She suffered from insomnia, and had some attacks of dyspnœa, after one of which she died, about three weeks after admission. The post mortem examination by Dr. Ogle revealed pallor and slightly yellowish tint of

See Addison's Collected Works (New Sydenham Society), p. 2r2. The passage is quoted by Dr. Pye-Smith in Virchow's Archiz', vol. lxv, p. 507; by Dr. S. Mac-

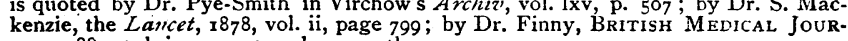
kenzie, the Lalcet, 1878, vol. ii, page 799; NAL, 1880, vol. i, page 5 ; and many others.
+ See Dr. S. Mackenzie's Lecture, loc. cit. 
the skin, slight œedema of the lower extremities, great pallor of the abdominal walls, fatty kidneys, frothy serum in the lungs, some ecchymoses in the larynx, a healthy heart containing little or no coagulum, but a small quantity of semifluid blood.

Lebert, ton, in 1853 , had recorded cases of fatal "puerperal chlorosis" at Zïrich-the seat of the subsequent observations of Gusserow and Biermer-and had spoken of these as examples of what he regarded as an "essential anæmia". Then, however, a long silence on the subject occurs in medical literature, broken only by the publication in Guy' Hospital Reports for 1857 of a series of cases by Dr. Wilks, under the head of "Idiopathic Fatty Degeneration", and of a case in the Lancet for 1863 (vol. i, p. 518 ), by Dr. Habershon, in a paper on this subject. The patient in this case was a spare woman aged 40 , who had for many years been subject to attacks of vomiting, which for eight months before her admission had been almost of daily occurrence. She had much gastralgia, pain in the back and limbs, and was very pallid. The attacks of pain were renewed with much severity. She, however, improved, and left the hospital, to return a year later, "blanched, emaciated, and extremely feeble". No gastric disturbance was presen now, only an extreme degree of asthenia and anæmia, under which she sank in two months. The necropsy by. Dr. Wilks disclosed only in tense anæmia of organs, marked fatty degeneration of the heart, and slight passive effusions in the serous sacs. Thus, these observations showed that in the hospital of Addison, at any rate, the existence of the disease was recognised; and Dr. F. Taylor did good service in collecting all the cases observed there up to the year 1878-namely; as many as twenty-three.

Curious to learn whether the like experience had befallen the physicians of the MiddIesex Hospital, I have searched the post mortem records for any fatal cases which could be thought to have belonged to this class, and from 1844 to 1871 (excluding 1852 and part of 1851 ) can find only one unequivocal case, which, it will be seen, was associated with a certain amount of gastric disease. This case occurred in 1865 , its subject being a woman aged $5 \mathrm{I}$, who was admitted for extreme anæmia three days before her death. No satisfactory history could be obtained, save that she had become rather rapidly anæmic. The skin was of a peculiar yellow hue, and she suffered from constant vomiting during her brief stay in hospital. After death, the sallowness of the surface was noted, also a considerable layer of subcutaneous fat. There were effusion in the serous sacs, and cedema of the lungs. The heart was of normal size, contained a little fluid blood-no coagula; but the condition of its walls is not recorded. There was slight atheroma of the aorta. The spleen was small and normal; the kidneys small, and the seat of a few minute cysts. The gastric mucous membrane was thickened in the pyloric region, and the seat of a small polypus, $R e$ cent homorrhage had occurred under the dura mater, and the brain was bloodless. Of other cases which come less clearly under this category, I find one, in 1844 , of a woman, complicated by old pulmonary tubercle and recent pneumonic hepatisation; one of a boy aged 8 , in I857, thin and sallow, with slight serous effusions, ecchymoses in the heart, which is described as "yellowish, mottled, and very fatty", the liver of a deep yellow-brown colour, with bleeding points and white specks on the surface; and one, in the same year, of a man aged 35 who died suddenly of fatty heart. These practically comprise all the cases within the period mentioned, with evidences after death of extreme anæmia and cardiac degeneration; other cases being chiefly those of cancer, renal disease, and purpura, one or two of which latter might possibly belong to the class in question. In $187 \mathrm{I}$, however, an undoubted case occurred under Dr. Greenhow's care, and was published by my friend and former colleague, Dr. R. King, then medical regis trar. I shall give the details of this case subsequently, but mention it now, because its publication antedated by a few weeks the appearance of an essay by Biermer, which did more than anything else to draw general attention to the subject.

Biermer's work must be taken in connection with that of Gusserow, who, in 1871 , published six cases of a fatal form of anæmia in preg. nant women; for both laboured in the same field. Biermer, who had previously related a case before a society at Dresden in 1868 , described and summarised, in the essay referred to, fifteen cases of a "peculiar form of prngressive pernicious anæmia, usually accompanied by fatty degeneration of the circulatory passages, and, secondarily, by hæmorrhages of the skin, retina, brain, and its serous membranes". This publication marked a distinct departure in the knowledge of this disease, and its taking but rather startling title assisted to draw attention to it. From that time to this, just ten years, a whole literature has sprung up around the subject. ${ }^{*}$ For a time, it was even thought that, * An analysis and review by M. Lépine in 1877 (Rev. Mensuelle) has facilitated
reference to this literature; but much has appeared, and continues to appear, since hat time. in this "progressive pernicious anæmia" of Biermer, a new disease had been discovered; but Drs. Wilks, Taylor, and Pye-Smith reasserted the claims of Addison, and proved conclusively that no new discovery had been launched upon the world. Nor has the new nomenclature been without its drawbacks. It designates more than is implied by the term "idiopathic", much as we may wish to banish that term from nosology, and it has rather obscured than emphasised that leading fact of the condition described by Addison. For, by the use of this terminology, authors have been led to class together cases of anæmia depending on known causes with those truly "idiopathic"; and some even speak of the supervention of pernicious anæmia in cases of cancer, for ex. ample. I shall show that this extension is perhaps justifiable, provided that, at the same time, a distinction be made between the cases which arise spontaneously and those where the anæmia is obviously secondary. At present, I will merely state my belief that pernicious anæmia includes, but does not comprise, idiopathic anæmia.

I have collected i io cases, including : most of those mentioned by M. Lépine in a review published in 1877. . The number might, I believe, well be doubled, before embracing all those cases which have been recorded. Seldom has such a mass of evidence bearing on any one disease been accumulated in, so, short a time; and yet it is not possible to arrive at a satisfactory solution of the question of its origin. It presents us, however, with the symptomatology of anæmia in its most severe form, and throws light apon the most marked lesion produced by anxmia. Of these-1 10 cases, 56 were males, and 54 females. The ages at which the patients often came under notice- - often only a short time before death-varied with the sexes; for, among the male cases, the majority, viz., 33, or 59 per cent., occurred between the ages of forty and sixty; and, among the female series-34, or 63 per cent.between twenty and forty.

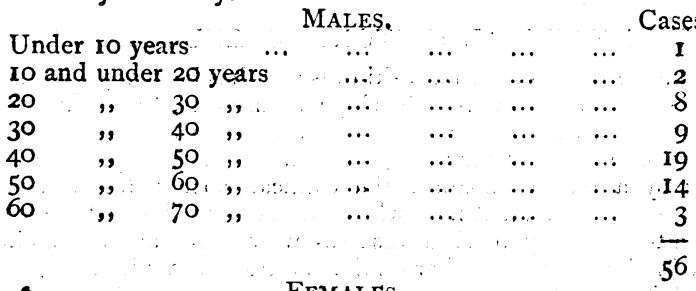

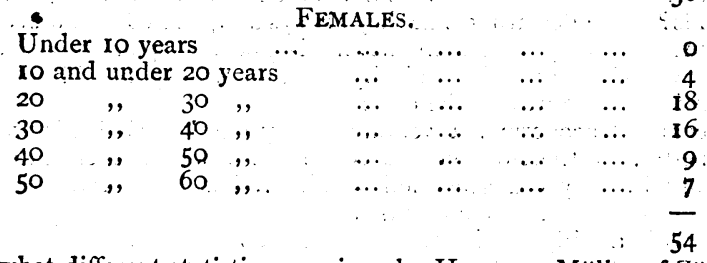

Somewhat different statistics are given by. Hermann Mitller of 'Zïrich*, who describes 44 cases from Professor Biermer's clinic, 9 only being males, and 28 of the 35 females being between the ages of twenty and forty.

\begin{tabular}{|c|c|c|c|c|c|c|c|c|c|c|c|}
\hline Are & & & $\gamma_{0}$ & & & Male & & & & emal & \\
\hline & & & & & Marr & d. $\mathrm{s}$ & gle. & & Mar & & Single. \\
\hline I 5 to 20 & years & $\ldots$ & 6 & $\ldots$ & 0 & $\ldots$ & 2 & $\ldots$ & 0 & $\ldots$ & .4 \\
\hline 21 to 30 & , , & $\ldots$ & I I & $\ldots$ & I & $\ldots$ & I & $\ldots$ & 7 & $\ldots$ & 2 \\
\hline 3 I to 40 & , , & $\ldots$ & 20 & $\ldots$ & o & $\ldots$ & I & $\ldots$ & $I 7$ & $\ldots$ & 2 \\
\hline 41 to 50 & , , & $\cdots$ & 4 & $\ldots$ & I & $\ldots$ & I & $\ldots$ & I & $\ldots$ & $\mathbf{r}$ \\
\hline $5 \mathrm{I}$ to 55 & , & $\ldots$ & 3 & $\cdots$ & & $2^{\circ}$ & & $\cdots$ & I & $\because$ & 0 \\
\hline
\end{tabular}

The preponderance of fenales corresponds to the period of child. bearing.

The onset of this severe affection is sometimes quite sudden-in such cases following severe mental shock or some violent emotion; or a profuse hæmorrhage, which at the time may threaten life, leaves behind it an anæmia which never disappears, and may become pernicious-i.e., may deepen in intensity in spite of treatment. More commonly, this exciting cause is added to a pre-existing and long-standing anæmia which then takes on a fatal form, or the determining event may occur in some other exhausting discharge. Leaving for the present the consideration of these prodromal influences, I may simply state now, that in many cases the onset is gradual and insidious, having perhaps in some cases a foundation in conditions of blood-impoverishment, but in others arising quite apart from such conditions. Or the patient may Smith. 
have been always below the standard of health as regards blood; may have suffered more than onee from extreme anæmia, and have regained the previous level, to be finally again lowered beyond restoration. However this may be, the symptoms which usher in the condition can all be attributed to it. There is a growing pallor of the skin and visible mucous membranes : a pallor frequently mingled with a yellowish tint, and even with a slight degree of actual jaundice; and the face becomes wax-like in appearance. At the same time, there is an increasing disinclination for physical exertion, partly from mere listlessness, partly from the breathlessness and palpitation which any physical effort evokes. The nutrition of the body is often well preserved; there may be, as Addison remarked, even an excessive amount of cutaneous'fat. Then, as the blood becomes more impoverished, dropsical effusions may appear in the eyelids and lower limbs; but such odema is not a constant symptom, and is generally late in its appearance. With the muscular asthenia, there is often complaint of pain in the limbs or back; and headaches, vertigo, and tinnitus are frequent. Sleep is sometimes, but not usually, heavy-a lethargic, drowsy state supervening towards the end, which may pass into semi-coma. But insomnia is a more constant symptom. Delirium may occur at the close, and sometimes convulsions. On the side of the digestive system, there is generally loss of appetite, it may be with actual intolerance of food ; and dyspepsia with nausea and vomiting is common. Indeed, vomiting stands out prominently among the symptoms of the disease-so common, so frequent, and so early in its occurrence, as to lend support to the views of Drs. Flint and Fenwick as to the essential dependence of obscure and fatal anæmia upon primary gastric derangement. Although in some cases such vomiting and other symptoms of gastro-intestinal disturbance do precede the appearance of the weakness and pallor, yet it is certainly not always so. Thirst, too, is marked in many cases: Gastralgia and epigastric tenderness are generally associated with the dyspeptic symptoms. Then, as to the intestines, diarrhœa is almost as often met with as vomiting, occurring sometimes early in the disease, sometimes just to wards the close, which it determines; and, although it is amenable to treatment, it may recur again and again with much severity. Constipation is not so common as diarrhœa.

As a rule, in the earlier stages, the breathing is quiet, except on exertion, which induces marked breathlessness; but, sometimes, at an advanced stage, attacks of dyspncea are frequent and painful, and may lead to a fatal result. In the cases I have had the opportunity of reading, I have not found this dyspnœa recorded as being of the peculiar ascending and descending rhythm, with a period of apnoea, known as Cheyne-Stokes respiration. The association of that type of respiration with fatty degeneration of the heart was noticed by its discoverers and though it occurs under other conditions also-e.g. uræmia, cerebral hæemorrhage, embolism, etc. - yet its association with fatty heart is stil accepted. As such degeneration is the most constant morbid lesion of anæemia, it is at least singular (if it be a fact) that this type of dyspnœa does not occur. As a rule, unless there be old disease in the lungs, there are no abnormal physical signs, except towards the end of life, when these organs become engorged, and serous effusions may take place in the pleura.

Attacks of syncope are liable to occur, but do not seem to be so frequent as might be imagined. The action of the heart is generally regula and quick, often very feeble. The impulse is often widely visible, un dulating, and thrilling; the area of procordial dulness is laterally increased; these signs are attributed by some to retraction of the lung; by others to dilatation of the heart itself. The so-called "hæmic" bruits are commonly, but not invariably, met with; a systolic blowing murmur at the apex and xiphoid cartilage, a bruit of coarser character simulating pericarditic friction at the base. The large arteries of the neck often visibly pulsate, and are the seat of loud murmurs. The jugula hum is seldom absent, and pulsation of the jugular vein is often observed. The pulse is soft and compressible, quick, jerking, and empty.

In all these symptoms there is nothing peculiar or special. They simply denote the presence of an anzmia of pronounced degree; - but there is one group of symptoms which occurs with such frequency in those severe forms as to be almost regarded as distinctive of them. I refer to the supervention of hamorrhages; and here it seems to me im portant to make some reservations. In several cases, hæmorrhages of one-kind or another-e.g., epistaxis, menorrhagia-take place in the prodromal period, and antedate the development of the anæmia, which they have much share in producing. Such hæmorrhages must be distinguished from others, often quite as profuse, which follow upon the appearance of the anxmia ; and, when appearing, they add greatly to the intensity of the disease. In a case, the particulars of which I shal presently narrate, the patient had been anæmic, and progressively' so, for years; then supervened profuse menstruation ; and, finally, a severe uterine hæmorrhage, which nothing would check till it carried her off.
Epistaxis, too, is common as a secondary result. Sometimes cerebral hremorrhage may ensue, and carry off the patient; but this is not common. More frequently, towards the close of life, petechial and purpuric eruptions occur; and beneath serous membranes and the dura mater ecchymoses are common, as well as in the substance of mucous membranes. In one very curious case, both in its rapid development, intense character, and as rapid recovery, recently recorded by Lachmann from Riegel's Clinic at Giessen, there developed, during the progress of the anæmia, a considerable tumour in the iliac region, with œdema of the lower limb on that side ; from its physical characters and manner of disappearance, it was conjectured (and with probable truth) that this swelling was due to $a$ hæmorrhagic effusion beneath the peritoneum. The patient was a young man aged 19 , and the an rmia had developed rapidly with no:other exciting cause than heavy walking through snow. That patient, like the great majority of those in whom the anæmia is profound, presented retinal hæmorrhages. These hæmorrhages and the other retinal changes, cedema of the disc; and neuro-retinitis, have been described and figured by Drs. S. Mackenzie and Gowers, the latter of whom says : "The extravasations are often numerous, and more or less striated or flame-shaped from their situation in the layer of nerve-fibres. They are usually most abundant around the optic nerve-entrance. They are frequently associated with white spots and areas, due in part to leucocyte-like cells, in part to degeneration in the disturbed retinal tissues. Occasionally, a pale spot may occupy the centre of a small hæmorrhage". (Manual of Medical Ophthalniology, page 190.) Quincke, in his 31 recorded cases, met with retinal hæmorrhages in all but 7 ; and notes the rapidity with which they disappear. We cannot, I think, regard them as invariably present; although their existence is a very valuable indication of the advanced stage of the disease. Moreover, as they are not commonly met with in other forms of anæemia, their presence has a certain diagnostic, as well as prognostic, value; but, on the latter point, Quincke gives cases which have recovered. Of the I10 cases (which include Quincke's), there are only 39 in which the ophthalmoscopic examination is recorded; and in 30 the hremorrhages were found; but only 17 were fatal cases, one left unrelieved, whilst no fewer than II were regarded as recovered. Of the 9 cases in which these hæmorrhages were absent, 6 were known to end fatally. I should not like to lay much stress upon such meagre statistics-especially as it is possible that the traces of previous hæmorrhage might have escaped the observers; but, so far as they go, they point to this : that retinal hæmorrhages do not imply a fatal termination, and that their absence does not necessitate a favourable prognosis.

There is usually no enlargement, or to only a slight degree, of either liver or spleen or lymphatic glands; and in only a very few cases has any special tenderness been noted over the bones.

Albuminuria, slight and transient, has been noted; but, as a rule, the urine is free from this abnormal constituent, of low specific gravity, mostly pale, sometimes high-coloured, and deficient in urea and uric acid; but the latter constituent is not diminished in proportion. Chlorides are reduced (Huguenin); but the excretion of phosphoric acid is said to be increased relatively to the nitrogenous matters (Edlefsen). A marked indican reaction was always observed by Huguenin. In one case recorded by Dr. Finny of Dublin (BRItish MEDICAL Journal, vol. i, I880, p. 44), the interesting observation was made by Dr. Emerson Reynolds of an appreciable quantity (viz., 0.308 grains in 72 ounces of urine) of iron in the urine sixteen days after treatment by iron had been discontinued.

There remains another symptom of peculiar significance; viz, pyrexia. The charts before you, both from marked cases of the disease-one by Immermann, the other by Quincke-illustrate the irregular course taken by the temperature; and this often without any concomitant changes appreciable in the patient's condition. The former-Chart I (Deutsches Archiv fiur Klin. Med., xiii; p. 233)-is that of a single woman aged $3 \mathbf{I}$, who was under treatment at Basle from August 23rd, 1872, to September 19th. The case is of some interest; for she had chlorotic symptoms when the catamenia began, at the age of seventeen; but she apparently recovered completely. The symptoms dated from three weeks. before admission, when she bécame feverish and anæmic, and lost appetite. The anæmia rathet rapidly increased, and with it its cardio-vascular signs developed, bul no retinal hæmorrhages. An appreciable hemiparesis of the facial muscles and of the tongue made the diagnosis difficult, so that the possibility of ulcerative endocarditis was entertained. Some diarrhicea occurred towards the close of the case: Slight splenic enlargement (no increase of white corpuscles) was also present. The post mortem examination revealed, in addition to an enlarged firm spleen, only the anæemic condition of organs and fatty changes met with in pernicious anæmia. No brain-lesion was found to account for the facial and lingual paresis. The other case-Chart 2, No. II in Quincke's col- 
lection (Deutsches Archiv für Klin. Med., xx, p. : 1 )-is that of a woman thirty-three years of age, who had been married nine years and had two children, the younger of whom, aged four, she had suckled for six months. She came into hospital on May I Ith, 1876, having for five months suffered from debility, palpitation, and vertigo. She lived in very poor circumstances, and was admitted in an extremely weak and anæmic state. Cardio-vascular signs of anæmia were marked there were retinal hæmorrhages and odema; and the blood showed marked variations in the red corpuscles, their numbers being only 143,000 per cubic millimètre $(1-38$ th). Transfusion was performed on May 24th; and the chart shows the course of the temperature for the following days; so that its irregularities must, I suppose, hardly be considered as due to the anæmia alone. This patient recovered, left the hospital on August 25th, and was again seen in November, looking well nourished and healthy. The third chart (No. 3) is one where profuse menorrhagia was added to the anæmia, the details of which I propose to give directly. As a rule, the temperature is liable to sudden exacerbations, sometimes reaching remarkable heights (in one of Dr. Finny's cases, $106^{\circ}$ ) from a normal or nearly normal level; or it may have a more or less continuous course, varied by - such exacerbations. Exceptionally, there is no abnormal rise of temperature throughout. The apparently paradoxical event of fever occurring under conditions of diminished oxygenation-as in anæmia-is discussed by Immermann, who points out that the same obtains in leukæmia and Hodgkin's disease, between which affections and anæmia there is the cammon link of poverty in red corpuscles. He shows also that the temperature rises after copious venesection; and the instability of temperature in anæmic convalescents is well known. $\mathrm{He}$ is inclined, then, to relate the pyrexia to the reduction in red corpuscles below a certain point; not that it is produced by increased metabolism, but by the decay of the tissue-elements-their conversion from complex unstable compounds into more stable substances: a conversion which must be accompanied by the setting free of heat, although not requiring increased oxidation. And to this increased heat-production, combined probably with heatretention, he attributes the "anæmic fever" of these diseases. The blood has, when examined, been found to be altered; but I will speak of that when I come to discuss the pathogeny of the disease.

It is not easy to fix the duration of many cases. The patients themselves cannot tell when their anæmia began; and some have been, they say, pale all their life. Of the series of cases. I have collectedviz., 1 1o-I find that in 32 the total duration of symptoms was from one to six months; in 24, from six to twelve months; in 25, from one to two years; and the remaining 12 for periods exceeding twa years. As many writers only speak of many weeks or months, such estimation does not include all the cases; and in these cases, where the symptoms date back only a few weeks, there is often found a history of some antecedent anæmia, or a period of variable length of slight languor and ill-health.

There can be no doubt that pernicious anæmia is not invariably fatal. Cases of recovery have been recorded by Quincke and others, where all the symptoms have been marked. Dr. Finny gives a striking case; and of the series to which I have so frequently referred, no fewer than twenty are regarded by their observers to have recovered. Some of these did recover perhaps permanently, but of this it is not possible to speak with certainty, the last-recorded note often referring to them as being in perfect health; and these were cases which clinically were indistinguishable from those that ran a lethal course; some of them un. doubtedly were rescued by prompt transfusion, and others recovered under medicinal treatment; but their occurrence is encouraging, the natural tendency of the disease being undoubtedly towards death. Four cases passed away unrelieved; and four, after an apparent recovery lasting a few weeks or months, would relapse into the previous state, to again be temporarily restored to comparative health-once more to relapse without possibility of recovering. The greater number, however, die (86 out of 110 ) sooner or later (four of these after temporary recovery and relapse); the mode of death being a simple asthenia and exhaustion, or passage into a comatose condition, or in syncope, or by dyspnoea, or convulsions. To briefly paraphrase Mialler's vivid description of the manner in which death approaches : the distress attains a painful intensity, sleep is hindered by the constant beating in the head, the hum and roar in the ears, whilst the faculties become dim and unspeakably dulled. Vertigo and headache grow so severe, that even sunlight causes pain. The prostration and weakness are so great that spontaneous effort is annulled, and the slightest movement, even the weight of the bedclothes, is irksome, and the patient groans and sighs in his distress. Now and then, towards the close, the hunger for air grows excessive, complaints are made of the painfulness with which every breath is taken, and relief is begged from this tormenting need. Sume become so feeble, and sink into so deep a lethargy, as to cease to take interest in anything, or they lie impassive, breathing deeply and heavily, pale as a waxen figure, motionless as a corpse. Others toss restlessly from side to side, and in their delirium make vain efforts to escape, and then die suddenly from exhaustion. What is this but the picture of death from loss of blood-a loss, not from hæmorrhage, but from impoverishment of the blood in its chief elements?

The post mortem appearances show extreme pallor of the surface and viscera. There is often a considerable amount of subcutaneous fat, and frequently slight oedema of the lower limbs. Dropsical effusions, never to large amount, occur in the serous sacs. The blood is fluid, thin, and watery, and thin, pale clots are mingled with the fluid blood in the chambers of the heart. Hæmorrhages are met with in the form of subcutaneous ecchymoses, and similar extravasations beneath the pleura, pericardium, intestinal mucous membrane, and in the pia mater. Sometimes effusions of blood of large amount occur in the latter situation. But the brain is pale, bloodless, and "wet" from odema. The lungs are generally cedematous, and, owing to the fluidity of the blood, appear engorged in their dependent parts, contrasting with the marked anæmia of their other portions. Almost without exception the heart is in a state of fatty degeneration; its walls are pale, flaccid, and friable; the interior of the ventricles, and especially of the left ventricle, show irregular whitish stria running transversely across the muscular bundles, and especially the papillary muscles, an appearance to which Dr. Quain gave the name of tabby-cat striation. Microscopically the muscular fibres are pale, and destitute of striation, granular, or loaded with fatty molecules and cell-globules of various sizes. Opaque patches of fatty degeneration occur on the mitral value and stud the lining membrane of the aorta. Fatty degeneration of the lining membrane of the smaller arteries, and even of capillary walls (especially in the retina) are observed, and serve to explain the liability to their rupture and hæmorrhage. Sometimes, but not invariably, there is fatty degeneration of the liver and kidneys. The spleen, lymphatic glands, and suprarenal capsules do not show any changes from the normal, except sometimes slight enlargement of the spleen; but in some cases the bone-marrow is found to be of a red colour, and to show microscopical evidence of marked hyperplasia.

Such, in brief, are the essential features of progressive anæmia.

\section{ABSTRACT OF LECTURES}

\section{STRUCTURE OF THE SKELETON IN THE SAUROPSIDA.}

Delivered at the Royal College of Surgeons of England.

BY W. K. PARKER, F.R.S.,

Hunterian Professor of Anatomy in the College.

LECTURE IX.

THE pectoral arch in birds presents a long; narrow, and recurved scapula, without any suprascapula, and a coracoid fitted by its proximal end into the groove in the antero-lateral edge of the sternum. The coracoid is usually completely ossified. There is no distinct epicoracoid. A small bone called the scapula accessoria is developed on the outer side of the shoulder-joint in some birds. In the carinate birds, the glenoidal ends of the scapula and acromion are each divided into two processes; those of the former are called the glenoidal and acromial processes; those of the latter the acromial and clavicular. The glenoidal process of the scapula partly forms the glenoid cavity, and partly unites with the coracoid; whilst to its acromial process is attached the outer end of the clavicle. The glenoidal process of the coracoid unites with the scapula, and its clavicular process articulates with the outer surface of the clavicle. This latter process probably represents the procoracoid of the lacertilians. In the ratitæ, there is no distinct clavicular process.

In a few birds, such as the apteryx and some parrots, there are no clavicles; in others, as the emu and some other birds, they are separate, united only by fibrous tissue; but generally they are ankylosed together, and along with a bony process, which represents the interclavicle, alone form one bone. When the limb is at rest, the humerus is parallel with the axis of the body; the forearm is in a position between pronation and supination, and the manus is bent back upon the ulnar side of the forearm. The ulna is usually stronger and longer than the radius. There are only two carpal bones, situated respectively on the radial and ulnar aspects of the limb. 